\title{
Culture-led city brands as economic engines: theory and empirics
}

\author{
Beatriz Plaza • Pilar González-Casimiro • \\ Paz Moral-Zuazo • Courtney Waldron
}

Received: 8 October 2013 / Accepted: 21 November 2014 / Published online: 25 December 2014

(C) The Author(s) 2014. This article is published with open access at Springerlink.com

\begin{abstract}
Cultural re-imaging through iconic art museums aims to create symbolic capital for a place in the form of creative images, reputation and associations with innovation. While literature has long identified architectural uniqueness as a potential driver of brand competitiveness, we argue diffusion of that image is equally important. This work draws upon economic concepts from other cultural industries (such as film, music and art) to develop a framework for understanding how cultural brands are built: How reproducible images of singular architecture accumulate in the media to strengthen a brand. We then test an art brand's impact on visitors. This work aims to offer evidence that the Guggenheim Museum Bilbao brand generates tourism to the city of Bilbao. By understanding how iconic cultural infrastructures create symbolic capital, policy makers may better tailor similar culture-led branding strategies to other places.
\end{abstract}

JEL Classification Z1 Cultural Economics · R1 Urban Economics

\section{Introduction}

Art, beauty and taste have become important drivers in postmodern economic development, in which this symbolic capital has the potential to add much value to economic processes in postindustrial societies. From graphic design, architecture to music, these

\footnotetext{
B. Plaza (凶) · P. González-Casmiro · P. Moral-Zuazo University of the Basque Country UPV/EHU, Avda. Lehendakari Agirre 83, 48015 Bilbao, Spain

e-mail: beatriz.plaza@ehu.es

C. Waldron

5975 Sun Appello Ave, Las Vegas, NV 89122, USA
} 
forms can encourage new consumer behavior, inspire ideas that may generate new content to consume, and foster new technologies.

These cognitive constructs have long been identified as significant forces in economies and societies. Bourdieu (1984) recognized reputation, honor and attention as symbolic capital that could leverage economic and social class advantages for individuals and groups. The influence of this intangible content continues to grow as postindustrial places transition into cognitive-cultural economies (Scott 1997). In these systems, semiotic content and uniqueness can add significant value to the inputs and outputs of production. On the consumption side, consumers reacting to Fordist modes of production, seek cognitive meaning to complement material goods and desire distinction over sameness. Modern digital media posits people and entities to be "seen" by wider audiences, but at the same time, risks disappearance amidst an excess of information. As such, uniqueness becomes crucial to attracting attention. On the production side, knowledge takes its place as an important input in the production function of post-industrial innovation economies (Hospers 2008). The growth of knowledge relies on cognitive content and capital-like reputation ${ }^{1}$ (Ter Wal and Boschma 2009).

For this reason, culture-led place re-imaging continues to play a role in the economic development of cities (Kotler and Gertner 2002; Rantisi and Leslie 2006). Brands communicate the reputation and uniqueness of a place in order to attract the visitors and consequently generate business investment. In the case of art museums, public heritage investments in "superstar museums" (Frey 1998) such as the Centre Pompidou Paris, Tate Modern London, the Guggenheim Museum Bilbao, the Louvre-Lens, or Pompidou-Metz draw upon blockbuster exhibitions and superstar architects with the hope of attracting a cultural tourism base and re-imaging a city. Much work has evaluated the economic impacts of new tourism and surrounding industry development (Llop and Arauzo-Carod 2012), while other work has tried to explain why some museums become economic engines and others merely devour public funds (Plaza and Haarich 2009). Still, there has been less focus on the symbolic value of these structures: Precisely, how much it contributes to increase tourism demand. Quantifying culture-led branding effectiveness positions them to better estimate how many public resources are worth investing into image-building strategies.

This paper aims to develop an empirical framework for measuring how much visibility in press actually impacts tourist flows. We, first, review the literature about place branding, specifically within the context of culture and iconic art museums. This study focuses attention on understanding how art museums can create valuable place brands: Reproducible images of unique museum infrastructures are diffused through and reinforced by the media, which attracts visitors. We then develop an econometric model for tourism demand which includes iconic museum visibility as an explanatory variable.

\footnotetext{
1 This art-driven reputation can increase global actors' willingness to cooperate with the city's players, reducing transaction costs and increasing its international attractiveness (Plaza and Haarich 2013). The symbolic dimension of cultural facilities must be newly understood in the context of meanings and mental associations of art and culture brands (Scott 2014; Power and Jansson 2011). Part of building an effective brand of a cultural asset depends on understanding what drives these cognitive connections in their cities. Symbolic proximity can increase other types of proximity in the form of embeddedness, cognitive proximity and/or mental proximity (Boschma 2005).
} 
We use free web tools (such as Google News) to measure the visibility of a culture infrastructure, and we employ the methodology known as structural time series models (Harvey 1989) to analyze the evolution over time of tourism demand.

Next, we evaluate this framework through a case study that estimates the impact of Guggenheim Museum Bilbao's news visibility on tourist arrivals (domestic and foreign) to Bilbao. The Guggenheim Museum Bilbao (GMB) stands as one of the most famous examples of such an instrument for urban regeneration for it, along with a package of development strategies, that helped turn the polluted, industrial town into a more globally connected city. As we analyze separately the flows of domestic and foreign tourists, a multivariate structural time series model is employed. Our results address the question of the GMB's news visibility in terms of increased visitors to Bilbao. We then discuss the implications of our results for policy makers, the limitations of the method, and make suggestions for future work.

\section{Literature review}

Places are complex entities made up of numerous characteristics: environment, urban design, history, culture, politics, etc. A place brand can synthesize these components into an organized, unified image that signals content and differentiability (Kavaratzis and Ashworth 2005). A place brand can create a narrative about a locality in order to make it recognizable to outsiders and to develop a sense of community among insiders (Vivant 2011). A brand can simplify and reduce risk in the decision-making process. A brand's economic value rests in its ability to attract visitors. Cultural tourists and sometimes even highly skilled professionals choose where they travel, live or conduct business in part due to the uniqueness, culture, or reputation of a place (Florida 2002). To establish such a brand, policy makers draw upon a number of tools: associations with celebrities (the Beatles' Liverpool); iconic architecture and signature urban design (Sydney Opera House); event hallmarking (European Capital of Culture or the Olympics), iconic pieces of art such as Picasso's Guernica (Plaza et al. 2013), to name a few (Ashworth 2009).

Our interest here lies in image building through culture, as culture already plays a significant role in economic regeneration (European Commission 2010). While cultural branding is not limited to the realm of art museums, these pieces serve as a popular choice among policy makers in part due to the success of a handful of "superstar museums" that have had significant impacts on local economies (Rosen 1981; Frey 1998). These museums and their branches/franchises distinguish themselves with widely known painters and iconic architecture and enjoy global prominence with a large numbers of visitors every year. The first international branch of such a museum was the Guggenheim Museum Bilbao. In the 1990s, Bilbao pursued construction of the GMB as part of a larger urban scheme to address several local troubles: industrial crisis (Gomez 1998); high unemployment (Plaza 2008); heavy pollution; and violence from Basque separatists (Abadie and Gardeazabal 2003). Along with several other public policies, the museum impacted the economy by creating a new tourist base (economic diversification) and re-imaging the city. The new image (or brand) leveraged by such an iconic museum can give a city an advantage in competition for 
development resources ${ }^{2}$ Culture can break up path dependencies and lock-in effects so integral to old industrial operations (Grabher 1993).

An important question is how do iconic museums catalyze valuable brand development? Branding begins with a narrative (Vivant 2011) that is constructed both within and outside of a physical place (Power and Jansson 2011). On the inside, iconic buildings like the GMB draw upon culture and architecture to begin shaping a unique image of place. The narrative constructed by the GMB might be one describing a formerly depressed industrial city's transition into the postmodern era. Aesthetics and symbolic associations can evoke notions of technological innovation, creativity and culture as the structure becomes the ultimate synecdoche for all the planning efforts that revitalized and remade Bilbao. This semiotic content is an important input to the production of a brand that may attract visitors who value culture (Mattes 2012), business stakeholders who value innovation, or even media entities that value elegant narratives.

At the simultaneous creation of this inner narrative, a place image is further shaped and communicated outside of museum walls and city boundaries through "brand channels." These channels are made up of numerous but related entities that together project image and influence perception of a brand-generating space. An example of such a brand channel is the media. From artistic and glamor magazines to high profile papers like the New York Times, the media serves as "a conduit in image building and distributing information about particular locales" (Currid and Williams 2009, p. 7). The media reflects this inner narrative but also actively shapes it by determining what specific aspects of place to publicize. However, Currid and Williams (2009) also point out that while the media chooses what topics to report on, it makes these decisions facing high demand uncertainty. Photographers and newspaper writers can never be sure what will sell. So, to accommodate some of the risk associated with unpredictable consumer preferences, the media tends to document stories that have sold successfully before. It distributes information about the same topics over and over, so that imagery tends to accumulate. It is this accumulation of images (accumulation of semantic connections and mental associations) through multiple brand channels that really drives the development of a valuable image.

Just like movies, music recording and literature, images of emblematic buildings are reproducible, characterized by strong scale economies at the reproduction stage (Schulze 1998). Though the initial cost of producing a piece of music is high, once it is recorded it is easy and cheap to duplicate. Similarly, once an iconic museum is built, the marginal cost of reproducing its unique image is nearly zero (due to new digital media). In the case of the Guggenheim Museum Bilbao, its image is being reproduced through many mediums: from online news publications and musical video clips to Facebook and Flickr accounts. Thus, reproducible images are not competitive based only on cost. Rather, they acquire value through the breadth of the audience they reach. They are also competitive through distribution. Authors have similarly argued

\footnotetext{
2 High initial costs coupled with unpredictable returns make investment in iconic art museums highly risky. Some projects like the GMB have generated enough jobs, related sector development and tax revenues to recoup their initial investments (Plaza 2006; Plaza et al. 2011). However, not all cultural institutions have fared as well. Neither the new wing at the Milwaukee Art Museum nor the Los Angeles Museum of Contemporary Art (MOCA) attracted their respective projected numbers of visitors (Grodach 2010; Plaza 2006). Not all cultural investments later evolve into economic drivers.
} 
products in the film (Askoy and Robins 1992) and music (Power and Hallencreutz 2007) markets compete not only based on the quality endowed from local production processes, but also based on their access to larger distribution networks. For example, audiences do not choose what films to watch based only on price or production costs. The ticket price at the theater for a $\$ 150$ million film is the same as the ticket price for a $\$ 10$ million film. Their choices largely depend on what is accessible to them: What films are showing at the cinema, on television, or in online streaming stores. As Askoy and Robins (1992) assert at the Cambridge Journal of Economics:

[The success of a film] depends almost completely on how well the cultural and aesthetic preferences of the consumer are anticipated, nurtured and channeled

... [T]he crucial bottleneck in the film business (and in other cultural industries)

is to do with building audiences.

When the cost of reproducing images is low, value comes from broadening a consumer base through tapping into preferences and reaching audiences ${ }^{3}$ Whereas uniqueness gives an inner narrative a competitive edge, distribution on the outside gives images a market advantage.

Still, how can a structure that was new in 1997 still have an impact on public opinion in 2013? Like many cultural goods, reproducible image consumption can be highly addictive. As Stigler and Becker (1977) point out in the case of music, the utility derived from the consumption of music depends on the consumed quantity, as well as the ability to appreciate music, which in turn is a function of past consumption of music. In the case of place re-imaging, the broader the diffusion of images of Frank Gehry's virtuoso architecture, the more often these images enter the public psyche, and the more the public will want to consume these images (Plaza 1999). Modern technology expedites this process, as the Internet and broadband mobile technology have ubiquitously expanded the distribution channels of branding content. Gadgets from computers to smartphones make newspaper articles, photographs, books, music, videos, blogs and "tweets" available at any moment in almost any place, providing cities new kinds of opportunities to communicate with the world.

To summarize, an art museum can create branding capital through the narrative, associations and images shaped on both the inside and the outside of place. The architecture itself, a non-reproducible piece of art, endows the brand with uniqueness, while brand channels like the media diffuse reproducible images at accelerating rates. The demand for these images increases as consumers absorb them (due to increasing returns to utility). Image accumulation fuels increasing demand for place, which reinforces a brand and ultimately attracts cultural visitors.

\section{The empirical framework}

So far, we have discussed the ability of culture-driven re-imaging to attract visitors to a destination and consequently promote local economic development. In short, an

\footnotetext{
3 Broadening audiences may also reduce some of the risk involved in iconic cultural projects. Following the same media logic outlined by Currid and Williams (2009), reaching more people increases the likelihood a cultural infrastructure will appeal to consumer tastes (Ateca-Amestoy and Prieto-Rodriguez 2013).
} 
iconic cultural brand can drive the tourist demand at local level. In this section, we develop an empirical framework for testing this theory. We focus attention on tourism demand analysis: We define a proxy variable for the visibility of the brand, and we test whether this variable affects the tourism demand.

The first question is how to measure brand visibility. A brand requires visibility, and the visibility is achieved through media. So, we propose to measure brand visibility by an indicator of the diffusion of the cultural infrastructure in the media. This indicator comes from Google News that provides data about the number of news items published in worldwide news sources using a certain keyword within a given time period. As a starting point, we compute the total items without any discrimination or weighting scheme. Then, at all times, we determine whether positive news (what we call positive environment) or negative (negative environment) dominate. The underlying assumptions to this are the following: First, every time there is a kind of news (positive or negative) that dominates the media, and second, the effects of positive news and negative news are different. We expect that a successful cultural brand tries to keep a stream of positive news, resulting in a positive environment that stays in time. We consider the following general tourism demand function: ${ }^{4}$

$$
y_{t}^{i}=f\left(\mathrm{INC}_{\mathrm{t}}^{i}, P_{t}^{i}, \mathrm{GN}_{t}, \operatorname{Trend}_{t}, \text { Seasonality }_{t}, \text { Dummies }_{t}\right)
$$

where $y_{t}^{i}$ stands for tourism demand from origin $i$; $\mathrm{INC}_{t}^{i}$ is an indicator of real income in origin $i ; P_{t}^{i}$ is a tourism price index that represents the relative cost of living in the destination to that in the origin $i$ adjusted by the exchange rate; $\mathrm{GN}_{t}$ is the number of online news about the cultural infrastructure registered in Google News, as stated above. Usually, all these variables are transformed to their natural logarithms, so the parameters of the model can be interpreted as elasticities. In addition, some dummies can be included to capture the effects of, for example, Easter holidays, one-off events or environment changes. In the latter case, an interaction between the dummy for environment change and $\mathrm{GN}_{t}$ must be included in order to measure the change on the elasticity given by the different type (positive or negative) of news.

The model is completed with two other components that are usually present in tourist time series and are possible sources of non-stationarity: trend and seasonality. The non-stationarity of the variables has to be taken into account when specifying the econometric model in order to avoid spurious regression results. The framework we propose to deal with these non-stationary components is based on structural time series models (STSM) given by Harvey (1989). The STSM belong to the class of unobserved component models, and they present several advantages. These models are specified directly in terms of trends and seasonality so they enable us to deal with the non-stationary characteristics of the series without having to transform the data, taking differences for instance. Furthermore, these models specify the unobserved components stochastically so they can evolve over time following the changes observed in the data. Therefore, the STSM include the deterministic trends and seasonality as a particular case. In this way, the results of estimating the model will indicate whether

\footnotetext{
${ }^{4}$ See, for example, Song and Witt (2000) or González and Moral (1995).
} 
these components are deterministic or not. In short, the STSM framework makes it possible to measure how a series responds to external factors (online news) while at the same time including components, such as time-varying trends and seasonal cycles to capture the non-stationary behavior of the series.

Two final elements complement the empirical model. First, in order to capture the dynamics of tourism demand, the model commonly includes lagged values of the explanatory variables, i.e., autoregressive distributed lag models are used. To specify the lag structure, we use a general-to-specific approach (Athanasopoulos et al. 2011; Hendry 1986). For example, with quarterly data, the initial general model with four lags of the explanatory variables is estimated. Then, a sequential elimination process is performed: At each step, the variable with the highest $p$ value is dropped, until all remaining variables have a $p$ value no greater than $10 \%$.

Second, frequently, the objective of the analysis is to determine the differences on $n$ different flows of tourist by origin. Then, the demand Eq. (1) is applied to each origin $i=1, \ldots, n$ resulting in a multivariate demand model. Given that all the tourists flows are subject to the same overall environment, such as prevailing business climate, world tourism trends, ..., we propose to use a multivariate STSM where it is assumed that these $n$ endogenous variables are not subject to any cause-andeffect relationship between themselves. This model is a time series analog of the seemingly unrelated regression equation model, so it is usually referred to as a system of seemingly unrelated time series equations, a SUTSE model (Harvey 1989).

\section{The model for Bilbao and the Guggenheim Museum}

To recapitulate, the methodology applied to quantify the influence of the news published about the GMB in attracting visitors to Bilbao is based on time series econometrics models. There are several indicators used in the literature to measure tourism demand such as number of tourists, total overnights stays, tourism revenues, among others. In this study, the dependent variable will be the number of visitors to Bilbao and the explanatory variables include not only the image of the museum but all the other factors that may affect these visits.

The Basque Statistics Institute provides data on the number of travelers to hotels in Bilbao by country of origin. This enables us to analyze the effect of online press on domestic visitors (DV) and foreign visitors (FV) separately and compare the results. Figure 1 shows the evolution over time of the dependent variables, visitors to Bilbao by origin. It can be observed that these series display changing trends that may be due to the evolution in general economic conditions. Besides, both series of visitors present seasonal behavior which is not constant over time. This seasonality is particularly noticeable in foreign visitors.

To define the explanatory variables related to the online image of Bilbao, we employ a method developed by Plaza et al. (2013) to collect data about the amount of images, or keyword references, published online. First of all, it has to be taken into account that not only the Guggenheim Museum Bilbao contributes to the making of the city image. Other topics may affect Bilbao's online visibility in news and Web 2.0 sites (such as Youtube, Flickr, Facebook, etc.), such as the Athletic Bilbao soccer team, the Fine Arts 


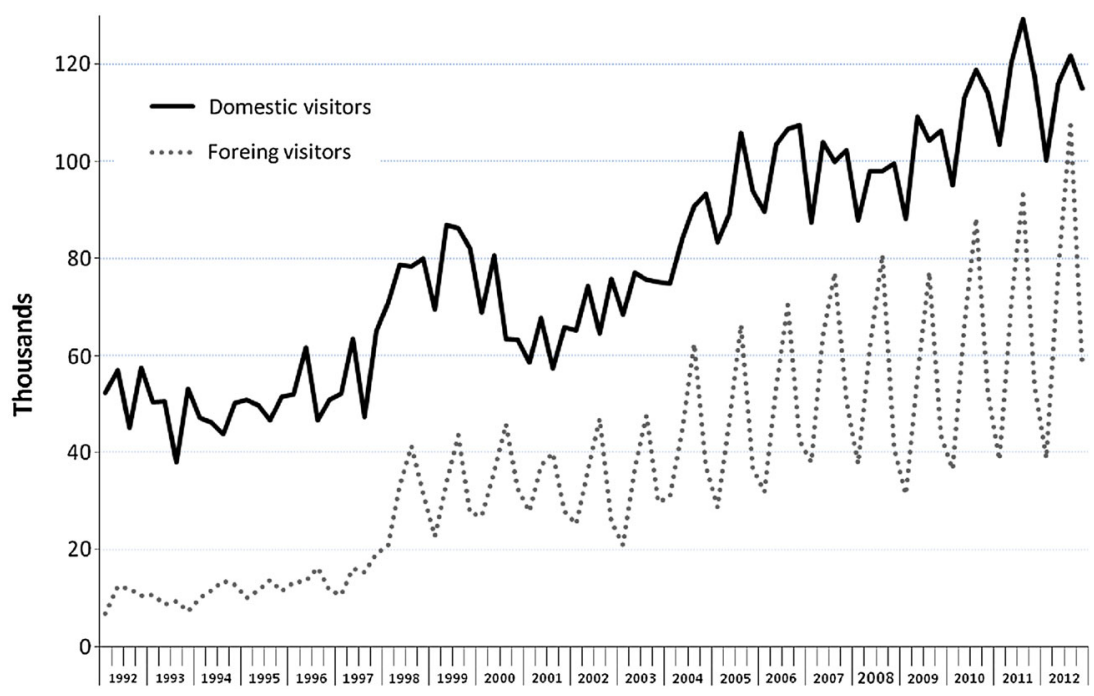

Fig. 1 Travelers to hotels in Bilbao by origin (1992-2012)

Museum, the Iberdrola energy company or the activity of ETA, a Basque separatist group, among others. Second, not all the topics will affect the image of Bilbao in the same way. While a positive effect can be expected from news about museums, soccer teams or big companies, it is clear that the contribution of the ETA group may be negative when news are related to violent actions and positive when they announce truce periods. Due to the large number of topics that should be considered, in principle, as candidates to create the image of Bilbao, a preliminary factorial analysis has been carried out to select the most relevant ones. This analysis identified a relationship between tourist flows and online traffic hits to two main topics: the Guggenheim Museum Bilbao and ETA.

We use Google News to collect quarterly data from the first quarter of 1992 until the second quarter of 2012 about the number of news items published about the GMB (GMBN) and the number of news items published about ETA (EN), which will be considered in the model as explanatory variables. It can be observed in Fig. 2 that these series display changing trends, with an increase in the rate of growth in news from year 2006.

The results of the Granger-causality tests performed show that, at the $5 \%$ significance level, past visitors (domestic/foreign) values do not influence future values of news about neither GMB nor ETA.

The model we propose for our study is a bivariate structural time series model that includes trend, seasonality and explanatory variables with finite distributed lags in order to capture the dynamic causal effect of online news on visitors. Since the variability of the visitors and news series increases over time (see Figs. 1, 2), a logarithmic formulation is proposed for the model.

$$
\ln Y_{t}=\mu_{t}+\gamma_{t}+\lambda \text { Easter }_{t}+\alpha_{4}(L) \ln X_{t}+\varepsilon_{t} \quad \varepsilon_{t} \sim \operatorname{nid}\left(0, \Sigma_{\varepsilon}\right)
$$



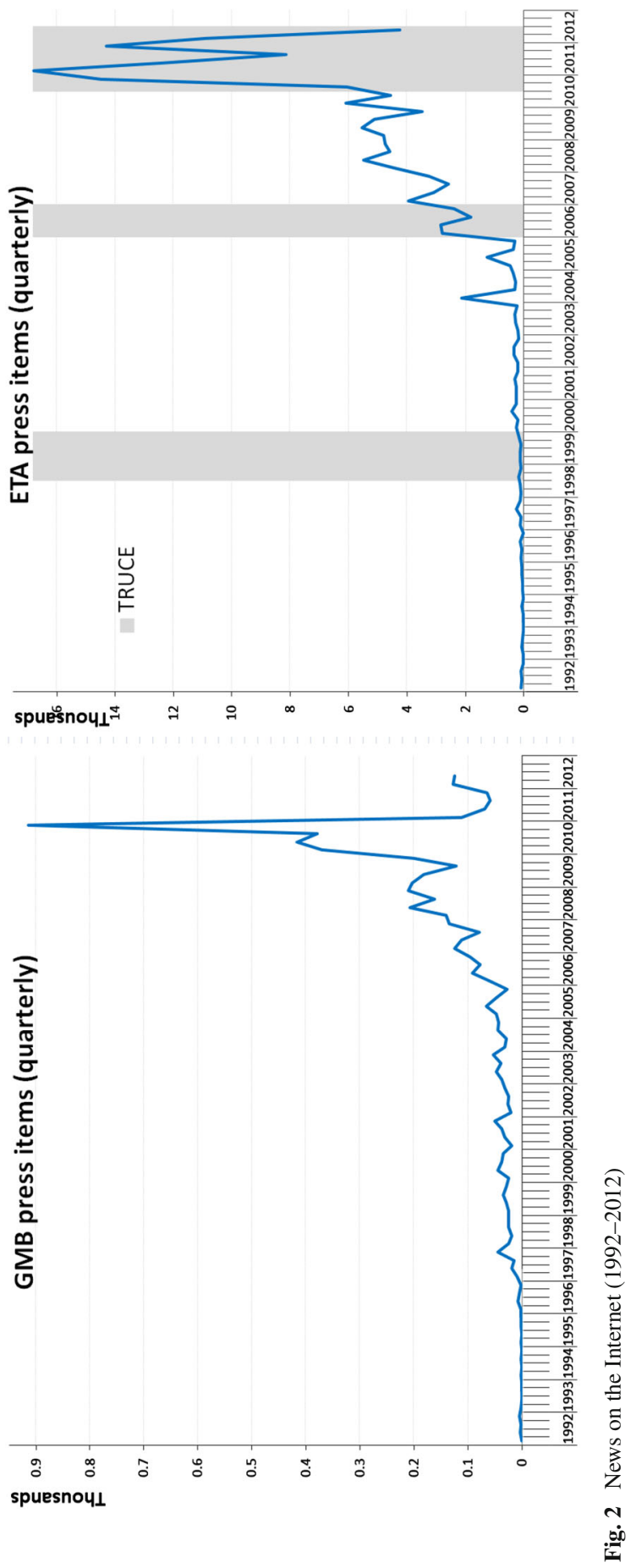


$$
\begin{aligned}
\mu_{t} & =\mu_{t-1}+\beta_{t}+\delta I_{t}+\eta_{t} \quad \eta_{t} \sim \operatorname{nid}\left(0, \Sigma_{\eta}\right) \\
\beta_{t} & =\beta_{t-1}+\zeta_{t} \quad \zeta_{t} \sim \operatorname{nid}\left(0, \Sigma_{\eta}\right) \\
\gamma_{t} & =-\gamma_{t-1}-\gamma_{t-2}-\gamma_{t-3}+\omega_{t} \quad \omega_{t} \sim \operatorname{nid}\left(0, \Sigma_{w}\right)
\end{aligned}
$$

where $\ln Y_{t}=\left[\ln D V_{t} \ln F V_{t}\right]$ refers to a vector of $\log$ domestic visitors and log foreign visitors to Bilbao and the factors that explain the number of visitors to Bilbao consist of a trend, $\mu_{t}$, a seasonal component, $\gamma_{t}$, a dummy variable to take into account the possible effect of Easter holidays on tourism flows and the explanatory variables, $X_{t}$.

The specification of the trend component relies on a stochastic formulation that allows the level, $\mu_{t}$, and the slope, $\beta_{t}$, of the trend to vary slowly over time [see Eqs. (3-4)]. A time-varying trend might respond to the evolution over time in the general economic conditions, such as transportation costs, evolution of the international tourism flows, ... (González and Moral 1995). An intervention variable, $I_{t}$, is included in the trend to capture the effect on visitors of the opening of the Guggenheim museum in the last quarter of 1997. This variable takes value 1 for the observation corresponding to the fourth quarter of 1997 and 0 otherwise. Equation (5) specifies the quarterly seasonal component, $\gamma_{t}$, stochastically so that it can reflect the changes undergone by the seasonal pattern of visitors to Bilbao during the sample period.

The explanatory variables, $X_{t}$, are the online news about GMB (GMBN) and about ETA (EN), income and prices. Concerning the effect of ETA news on the number of visitors to Bilbao, it is necessary to distinguish between the effect of ETA news in periods of truce (see the gray areas in Fig. 2) and in periods of no truce. To achieve this goal, we include in the model an interaction variable, TEN, that takes the value EN if observation $t$ belongs to a truce period and zero otherwise. As regards income, real personal disposable income would be the most appropriate indicator. These data are not available, and the index of GDP per head $(2005=100)$ for the UE countries (GDPUE) is used as a proxy for foreign visitors' income and the index of Spanish GDP per head (GDPSP) for domestic visitors. The relative price indexes for foreign visitors (RPF) and domestic visitors (RPD) are defined as the ratio of the Basque Country $^{5}$ CPI and the UE15 CPI for foreign visitors, and the ratio of the Basque Country CPI and the Spanish CPI for domestic visitors, respectively. These data all come from OECD historical series but the Basque Country CPI, which is published by the Spanish National Statistics Institute. Finally, a matrix polynomial in the lag operator of order 4 is applied to all the variables included in $X_{t}$ to capture the possible delays in the effect of the explanatory variables on visitors.

With respect to the error terms of the model, we assume that the irregular disturbance in Eq. (1), $\varepsilon_{t}$, the level disturbance, $\eta_{t}$, the slope disturbance, $\zeta_{t}$, and the seasonal disturbance, $\omega_{t}$, are bivariate white noises mutually uncorrelated and with covariance matrices, $\Sigma_{\varepsilon}, \Sigma_{\eta}, \Sigma_{\zeta}$ and $\Sigma_{\omega}$, respectively. In the SUTSE models, the two dependent variables are linked together by allowing the various components to be contemporaneously correlated. The link among the series through the off-diagonal elements of these disturbance covariance matrices might give more efficient estimates than modeling each series in a univariate fashion.

\footnotetext{
5 Bilbao is the largest city of the Basque Country, an autonomous community of northern Spain.
} 


\section{Estimation results}

The sample period chosen for estimating model (2-5) runs from the first quarter of 1992 to the second quarter of 2012. The unknown parameters of the model are given by the Easter effect, $\lambda$, the regression coefficients in matrix $\alpha_{4}(\mathrm{~L})$, the covariance matrices of the unobserved components, and the vector of coefficients of the intervention variable included in the trend component vector, $\delta$. The estimation of this model is performed using ST AMP8.0 $0^{T M}$ (see Koopman et al. 2007), which is a module of Oxmetrics 5.0 $0^{T M}$ (Timberlake Consultants Ltd., London, UK).

Preliminary results of estimating model (2-5) show that the dummy for Easter effect, prices, and some of the lagged explanatory variables included in the model are not relevant so they can be excluded from the model. The results of the estimation of the parameters of a simplified version of model (2-5) are shown in Table 1, while Table 2 shows the following diagnostics: the residual autocorrelation coefficients of order 1 and 4,r(1) and $r(4)$, the Box-Ljung statistic $Q(4)$ based on the first 4 residual autocorrelations, a heteroscedasticity test $H(23)$, and JB is the Jarque and Bera statistic for testing normality. The conventional coefficient of determination, $R^{2}$, is not very useful as a measure of goodness of fit when analyzing time series that exhibit strong upwards or downwards trends and/or seasonal cycles. Harvey (1989) proposes a new coefficient of determination, $R_{S}^{2}$, substituting the observations by the first differences of the series around the seasonal means. It can be observed that the diagnostics are quite satisfactory for the estimated model.

The results obtained for the coefficients of the variables related to online news show that the distribution over time and the magnitude of the effect of these news are quite different for each type of visitors. Thus, a $1 \%$ increase in the number of articles about

Table 1 Estimation results on visibility on the Internet

\begin{tabular}{|c|c|c|c|c|c|c|c|c|}
\hline & \multirow{2}{*}{$\begin{array}{l}\text { GMB } \\
\text { opening } \delta\end{array}$} & \multicolumn{3}{|c|}{ GMB press items } & \multicolumn{4}{|c|}{ ETA press items } \\
\hline & & $\mathrm{GMBN}_{t}$ & $\mathrm{GMBN}_{t-1}$ & $\mathrm{GMBN}_{t-4}$ & $\mathrm{EN}_{t}$ & $\mathrm{EN}_{t-2}$ & $\mathrm{TEN}_{t}$ & GDPUE $_{t}$ \\
\hline $\mathrm{DV}^{\mathrm{a}, \mathrm{b}}$ & $\begin{array}{l}0.2034^{* * *} \\
(0.0637)\end{array}$ & $\begin{array}{l}0.0456^{* * *} \\
(0.0159)\end{array}$ & - & $\begin{array}{l}0.0444^{* * *} \\
(0.0142)\end{array}$ & $\begin{array}{l}-0.0368^{* *} \\
(0.0147)\end{array}$ & - & $\begin{array}{l}0.0126^{* * *} \\
(0.0039)\end{array}$ & - \\
\hline $\mathrm{FV}^{\mathrm{a}, \mathrm{b}}$ & $\begin{array}{l}0.5162^{* * *} \\
(0.1036)\end{array}$ & & $\begin{array}{l}0.0501^{\text {** }} \\
(0.0221)\end{array}$ & & & $\begin{array}{l}-0.0373^{*} \\
(0.0214)\end{array}$ & & $\begin{array}{l}3.225^{* *} \\
(0.0235)\end{array}$ \\
\hline$\widehat{\Sigma}_{\eta}=$ & {$\left[\begin{array}{l}0.0018 \\
0.0016\end{array} 0.0\right.$} & & $\widehat{\Sigma}_{\zeta}=0$ & $\widehat{\Sigma}_{\omega}=\left[\begin{array}{l}0.0 \\
0.0\end{array}\right.$ & $\begin{array}{ll}0007 & \\
0012 & 0.0003\end{array}$ & & $\widehat{\Sigma} \varepsilon=\left[\begin{array}{l}0 . \\
-\end{array}\right.$ & $\begin{array}{ll}009 \\
0006 & 0.0012\end{array}$ \\
\hline
\end{tabular}

a Asymptotic standard errors in parentheses

$\mathrm{b} *, * *, * * *$ Statistically significant at 10,5 and $1 \%$ levels

Table 2 Diagnostic tests

\begin{tabular}{lllllrr}
\hline Variable & $r(1)$ & $r(4)$ & $Q(4)$ & $H(23)$ & \multicolumn{1}{l}{$\mathrm{JB}$} & $R_{S}^{2}$ \\
\hline Domestic visitors & 0.1058 & 0.0439 & 2.3019 & 0.2633 & 0.4122 & 0.5958 \\
Foreign visitors & 0.0211 & -0.0463 & 1.5655 & 0.2358 & 54.9404 & 0.6361 \\
\hline
\end{tabular}


the Guggenheim Museum Bilbao published in Google News leads to an immediate increase in the domestic visitors to Bilbao of $0.0456 \%$ and a 4-quarter lagged increase of $0.0444 \%$, whereas the number of foreign visitors increases by a $0.0501 \%$ one quarter after the news publication occurs. Meanwhile, it can be observed that the number of articles about ETA published in Google News affects both the number of domestic and foreign visitors but with different dynamics. A $1 \%$ increase in the number of news about ETA leads to a contemporaneous decrease of domestic visitors and to a 2-quarter lagged decrease of $0.0373 \%$ for foreign visitors. It should be noted that the estimated impact effect of the articles about ETA on domestic tourism is different depending on the truce periods: A $1 \%$ increase in the number of articles about ETA is estimated to decrease domestic visitors that quarter by $0.0368 \%$ in periods of no truce and $0.0242 \%$ in truce periods, while the truce seems to have no effect on foreign visitors.

The graphs in Fig. 3 show the estimates for the trend and seasonal components for the two original series of domestic and foreign visitors. With respect to the trend component, Table 1 shows that the estimation of the variance for the slope component is zero for both series, so we have trends with deterministic slopes but stochastic levels for both series. Furthermore, the level disturbances are also positively correlated $(r=0.5085)$. The intervention variable included in the trend component is statistically significant both for domestic and foreign visitors. This result means that the opening of the GMB had a very positive effect in attracting visitors to Bilbao, particularly foreign visitors. Two clear features could be noted in the evolution of the trends. One is the above-mentioned increase in the number of visitors due to the opening of the Guggenheim museum that is followed by an increase in the number of visitors with higher rates of growth in the case of domestic visitors from 2001. The second one is the change in the trend in the year 2008 mainly for domestic visitors due, probably, to the world economic crisis.

The right-hand side graph in Fig. 3 shows the differences in the seasonal pattern between domestic and foreign visitors. Foreign visitors' seasonality is much more concentrated in the summer quarter, and its amplitude has been increasing throughout the sample. On the other hand, the amplitude of the seasonal component of domestic visitors is narrower and there are positive seasonal effects in the spring and summer quarters.

To summarize our findings, newspaper publicity about the GMB significantly affects the number of visitors, while publicity about ETA deters potential visitors to Bilbao, though this influence changes slightly during truce periods in the case of domestic visitors. It should be noted that the effect of the online news about GMB has been isolated from the effect of the opening of the museum by means of the intervention variable included in the trend. In this way, we have been able to estimate two net effects on the number of visitors: on one hand, the effect of the opening of the museum and on the other hand the effect of the online news. Both of them are statistically significant. It implies that, even disregarding the museum inauguration, the images related to GMB in the online media are important for attracting visitors to Bilbao. Therefore, we may conclude that our model supports the framework developed earlier: Images about the GMB in the online media accumulate at an increasing rate, which in turn attracts visitors to Bilbao. 

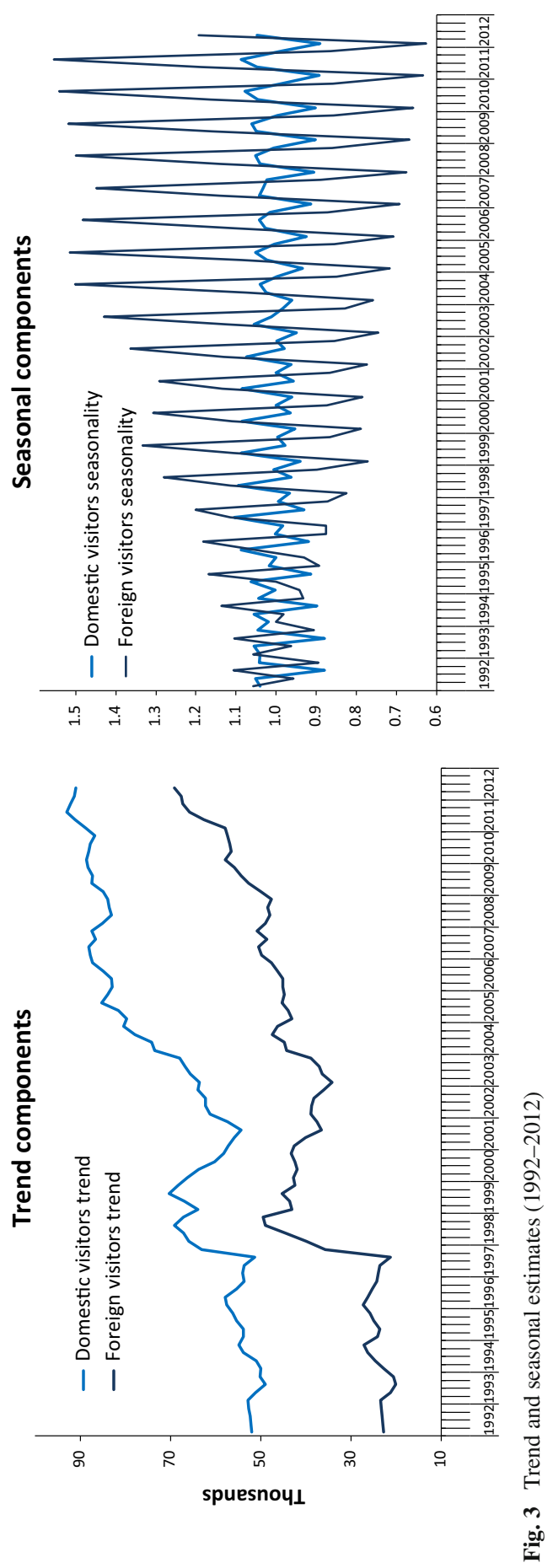
Then, what is the impact of GMB-driven news items on the number of visitors to Bilbao? The results show evidence that positive changes in online press visibility of the Guggenheim Museum Bilbao accompany positive and relevant changes in tourism to Bilbao. The total cumulative elasticities of online news about the GMB are $0.09 \%$ in the case of domestic visitors and $0.05 \%$ in the case of foreign visitors.

Given the results of the estimating model (2-5), it is possible to estimate the effect of online news about the GMB on the number of visitors both domestic and foreign for each period of time. Figure 4 shows the comparison between the raw data on visitors (solid line) and the estimated numbers of visitors discounting the effect of the GMB news (dashed line). The gap between the two series is a measure of the contribution of the online GMB news to the number of visitors to Bilbao.

According to parameter estimates, it can be observed that the influence of the GMB news is bigger for domestic visitors than for foreign visitors. This contribution is estimated to be between $24-28 \%$ of the total domestic visitors in the period 19982005 and between 15-18\% of the total foreign visitors. As we saw in Fig. 2, the GMB news stories increase rapidly from 2006 until 2010. This behavior leads, obviously, to an increase in the contribution to the visitors to Bilbao that can be estimated at between $36-40 \%$ for domestic visitors and between $22-25 \%$ for foreign visitors in the period 2008-2010.

Specifically for the period 1998-2005, between 18,369 and 21,430 visitors out of the total quarterly average of 76,536 domestic visitors to Bilbao can be attributed to the influence of the visibility of the Guggenheim Museum Bilbao in the online press. With regard to foreigners, between 5,398 and 6,477 quarterly visitors out of the total average of quarterly 35,985 foreign visitors can be attributed to the impact of the GMB in the online press. This contribution increases after the crisis. Thus, for the period 2008-2010, between 38,375 and 42,639 visitors out of the total 106,598 quarterly average of domestic visitors to Bilbao can be attributed to the influence of the visibility of the Guggenheim museum Bilbao in the online press. With regard to foreigners, between 12,752 and 14,491 quarterly visitors out of the total quarterly average of 57,963 foreign visitors can be attributed to the impact of the GMB in the online press in the same period.

In other words, the presence of the Guggenheim Museum Bilbao in the press exerts an important influence on the number of visitors to Bilbao. As has been proved in this article, to an extent, intangible image effects can be valued reliably. These figures denote the positive image (symbolic capital) the museum evokes.

\section{Implications for policy makers and researchers}

By offering quantified evidence that the GMB has created value for the city of Bilbao in the form of a symbolic capital, our results may have implications for policy makers both looking to apply similar cultural branding strategies to other destinations and also working to evaluate the impact of cultural infrastructures that are already standing.

First, our case study quantitatively illustrates that an art brand can have real economic returns. As our framework suggests, uniqueness of architecture and the diffusion of images are two crucial components to building a valuable brand. While the 

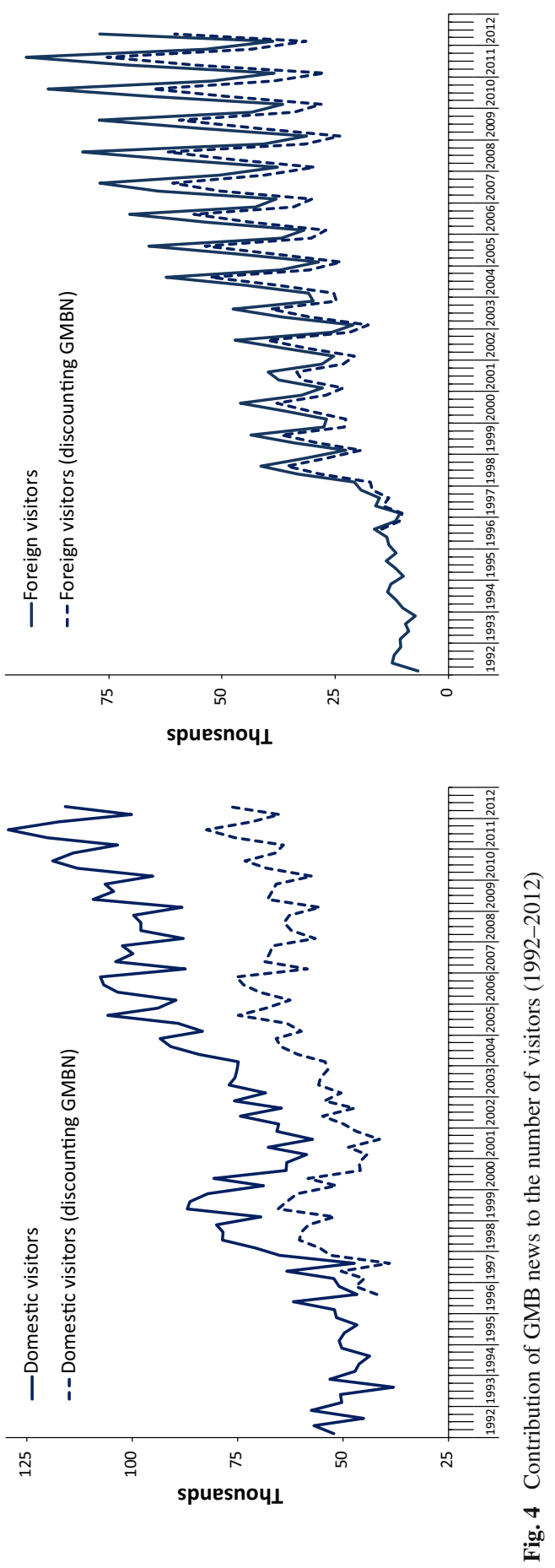
importance of uniqueness has been stressed by cultural economists (Frey 1998), policy makers must also consider connectivity when devising an image-building strategy. Well-known architects and international museum chains not only endow projects with distinction but also connect places into brand distribution mechanisms. Policy makers might consider the different parties involved in image distribution, such as the media, when devising branding strategies.

In addition to offering insight about the drivers in culture-led brand markets for future projects, this work proposes a method with which to evaluate the impact of the press on the number of visitors. If the economic value of its symbolic capital was not fully understood before, perhaps we may appreciate it now. Testing the model against other economic measures, such as foreign direct investment, could detect the presence of externalities produced by some cultural institutions. Indeed, other work has already recognized that cultural industries often give rise to externalities (European Commission 2010; Lorenzen et al. 2008). Such assessments are vital to appreciating the full value of cultural branding structures.

Nonetheless, the framework and methodology presented in this work need to be tested against other cases and other cities before such claims are put into practice. The GMB, as the first international outpost of a world class art collection, not only benefited from a first-mover advantage (thereby attracting more attention), but the museum also opened around the same time as the Internet boom. ${ }^{6}$ The heightened use of new media more than likely leveraged it an additional advantage in the form of more rapid information publication. Another concern is for how long images can accumulate before they level-off or saturate a market. Image overload could revise consumer preferences and their returns to utility. At what point does this happen, and would it weaken the brand? The developed framework, method, and results provide a constructive springboard for future research and policy analysis.

\section{Conclusions}

It has long been understood that iconic art museums can help re-image places for economic gains. We have sought to develop an explanation of how and for how much and test this framework with quantitative data. Within a city, an iconic art museum constructs a unique narrative by drawing upon semantic associations (mental connections) with culture, innovation, creativity, postmodernism, etc., which create symbolic value. Beyond place, brand channels like the media diffuse images of a singular piece of architecture and city, further crafting and publicizing the brand narrative. While the GMB itself is a non-reproducible unique and singular piece of architecture, its image is reproducible and allows its diffusion to reach a broad audience. The media, drawing upon previously published topics (images), increases image supply, while consumers

\footnotetext{
6 As stated by Plaza and Haarich (2013) "the GMB opened around the same time as the Internet boom started to have an effect on global communication and news transfer ...(..). The number of news items on the GMB increased even more to the extent that its silhouette was reported through North American news agencies, which enjoy a monopoly power worldwide at the time. The connection of the GMB to English-speaking, especially US media channels, acted as a huge loudspeaker worldwide, accelerating the branding effectiveness of the GMB."
} 
who may gain increasing returns to utility from image consumption increase demand. This image accumulation process (accumulation of semantic connections and mental associations) drives long-term branding. The Guggenheim Museum, designed by Frank Gehry, has generated real brand value for the city of Bilbao; real symbolic capital that benefits the regional economy. Specifically for the period 1998-2005, between 18,369 and 21,430 visitors out of the total quarterly average of 76,536 domestic visitors to Bilbao, can be attributed to the influence of the visibility of the Guggenheim Museum Bilbao in the online press. With regard to foreigners, between 5,398 and 6,477 quarterly visitors out of the total average of quarterly 35,985 foreign visitors can be attributed to the impact of the GMB in the online press. This contribution increases after the crisis. Thus, for the period 2008-2010, between 38,375 and 42,639 visitors out of the total 106,598 quarterly average of domestic visitors to Bilbao can be attributed to the influence of the visibility of the Guggenheim museum Bilbao in the online press. With regard to foreigners, between 12,752 and 14,491 quarterly visitors out of the total quarterly average of 57,963 foreign visitors can be attributed to the impact of the GMB in the online press in the same period. New methods for realizing the economic value of such intangible items will allow us to more efficiently cultivate culture-led development in the twenty-first century.

Open Access This article is distributed under the terms of the Creative Commons Attribution License which permits any use, distribution, and reproduction in any medium, provided the original author(s) and the source are credited.

\section{References}

Abadie A, Gardeazabal J (2003) The economic costs of conflict: a case study of the Basque Country. Am Econ Rev 93(1):113-132

Ashworth G (2009) The instruments of place branding: How is it done? Euro Spat Res Policy 16(1):9-22

Askoy A, Robins K (1992) Hollywood for the 21st century: global competition for critical mass in image markets. Camb J Econ 16(1):1-22

Ateca-Amestoy V, Prieto-Rodriguez J (2013) Forecasting accuracy of behavioural models for participation in the arts. Eur J Oper Res 229(1):124-131

Athanasopoulos G, Hyndman RJ, Song H, Wu DC (2011) The tourism forecasting competition. Int J Forecast 27(3):822-844

Boschma R (2005) Proximity and innovation: a critical assessment. Reg Stud 39(1):61-74

Bourdieu P (1984) Distinction: a social critique on the judgement of taste. Harvard University Press, Boston

Currid E, Williams S (2009) The geography of buzz: art, culture and the social milieu in Los Angeles and New York. J Econ Geogr 10(3):423-451

European Commission (2010) Green Paper: unlocking the potential of cultural and creative industries. European Commission COM (2010)183

Florida R (2002) The economic geography of talent. Ann Assoc Am Geogr 92(4):743-755

Frey B (1998) Superstar museums: an economic analysis. J Cult Econ 22(2/3):113-125

Gomez MV (1998) Reflective images: the case of urban regeneration in Glasgow and Bilbao. Int Urban Reg Res 22(1):106-121

González P, Moral P (1995) An analysis of international tourism demand in Spain. Int J Forecast 11:233-251

Grabher G (1993) The weakness of strong ties: the lock-in of regional development in the Ruhr area. In: Grabher G (ed) The embedded firm. Routledge, London, pp 255-277

Grodach C (2010) Beyond Bilbao: rethinking flagship cultural development and planning in three California cities. J Plan Educ Res 29(3):353-366 
Harvey AC (1989) Forecasting, structural time series models and the Kalman filter. Cambridge University Press, Cambridge

Hendry DF (1986) Empirical modeling in dynamic econometrics. Appl Math Comput 20:201-236

Hospers GJ (2008) Governance in innovative cities and the importance of branding. Innov Manag Policy Prac 10(2/3):224-234

Kavaratzis M, Ashworth GJ (2005) City branding: an effective assertion of identity or a transitory marketing trick? Tijdschrift voor Economische en Sociale Geografic 96(5):506-514

Kotler P, Gertner D (2002) Country as brand, product, and beyond: a place marketing and brand management perspective. J Brand Manag 9(4):249-261

Koopman SJ, Doornik JA, Harvey AC, Shephard N (2007) Time series unobservable analyser, modeller and predictor: STAMP8TM. Timberlake Consultants Press, London

Llop M, Arauzo-Carod JM (2012) Identifying the economic impact behind a cultural asset: an input-output subsystems analysis. Ann Reg Sci 49(3):861-877

Lorenzen M, Scott AJ, Vang J (2008) Geography and the cultural economy. J Econ Geogr 8(5):589-592

Mattes J (2012) Dimensions of proximity and knowledge bases: innovation between spatial and non-spatial factors. Reg Stud 46(8):1085-1099

Plaza B (1999) The Guggenheim-Bilbao museum effect: a reply. Int Urban Reg Res 23(3):589-592

Plaza B (2006) The return on investment of the Guggeheim Museum Bilbao. Int Urban Reg Res 30(2):452467

Plaza B (2008) On some challenges and conditions for the Guggenheim Museum Bilbao to be an effective economic re-activator. Int Urban Reg Res 32(2):506-517

Plaza B, Haarich SN (2009) Museums for urban regeneration? Exploring conditions for their effectiveness. J Urban Reg Renew 2(3):259-271

Plaza B, Galvez-Galvez C, Gonzalez-Flores A (2011) Testing the employment impact of the Guggenheim Museum Bilbao via TSA. Tour Econ 17(1):223-229

Plaza B, Haarich SN, Waldron CM (2013) Picasso's Guernica: the strength of an art brand in destination e-Branding. Int J Arts Manag 15(3):53-64

Plaza B, Haarich SN (2013) The Guggenheim Museum Bilbao: between regional embeddedness and global networking. Euro Plan Stud. doi:10.1080/09654313.2013.817543

Power D, Hallencreutz D (2007) Competitiveness, local production systems and global commodity chains in the music industry: entering the US market. Reg Stud 41(3):377-389

Power D, Jansson J (2011) Constructing brands from the outside? Brand channels, cyclical clusters and global circuits. In: Pike A (ed) Brands and branding geographies. Edward Elgar, Cheltenham, pp 150-164

Rantisi NM, Leslie D (2006) Branding the design metropole: the case of Montréal, Canada. Area 38(4): 364-376

Rosen S (1981) The economics of superstars. Am Econ Rev 71(5):845-858

Schulze G (1998) International trade in arts. In: 10th International conference on cultural economics, Plennary Session, Barcelona, 17 June

Scott AJ (1997) The cultural economy of cities. Int Urban Reg Res 21(2):323-339

Scott AJ (2014) Beyond the creative city: cognitive-cultural capitalism and the new urbanism. Reg Stud 48(4):565-578

Song H, Witt SF (2000) Tourism demand modeling and forecasting: modern econometric approaches. Pergamon, Oxford

Stigler GJ, Becker G (1977) De gustibus non est disputandum. Am Econ Rev 67(2):76-90

Ter Wal AL, Boschma RA (2009) Applying social network analysis in economic geography: framing some key analytic issues. Ann Reg Sci 43(3):739-756

Vivant E (2011) Who brands whom? The role of local authorities in the branching of art museums. Town Plan Rev 82(1):99-115 